\title{
Cloning, Expression and Purification of Vibrio parahaemolyticus L-type Lectin from White Leg Shrimp Litopenaeus vannamei for Bacterial Agglutinating
}

\author{
Phuong-Thao Thi Nguyen ${ }^{1,2,3}$, Lan-Vy Hoai Nguyen ${ }^{1,2}$, Thang Tan Nguyen ${ }^{3}$, Kim-Loan Thi Nguyen ${ }^{3}$, \\ Hieu Tran-Van ${ }^{1,2^{*}}$ \\ ${ }^{1}$ Department of Molecular and Environmental Biotechnology, Faculty of Biology, University of Science, Ho Chi Minh City, \\ Vietnam \\ ${ }^{2}$ Vietnam National University, Ho Chi Minh City, Vietnam \\ ${ }^{3}$ Department of Biotechnology and Crop Science, Faculty of Agriculture and Food Technology, Tien Giang University, \\ Tien Giang Province, Vietnam
}

*Address for Correspondence: Dr. Hieu Tran-Van, Associate Professor, Department of Molecular and Environmental Biotechnology, Faculty of Biology and Biotechnology, University of Science, Vietnam National University, Ho Chi Minh City, Vietnam

E-mail: tvhieu@hcmus.edu.vn; Fax Number: +842838350096

Received: 06 Jan 2020/ Revised: 02 Mar 2020/ Accepted: 10 Apr 2020

\begin{abstract}
Background- Acute hepato pancreatic necrosis disease is the most severe disease currently affecting brackish-water shrimp aquaculture in Viet Nam, sourced by toxin-producing strains of Vibrio parahaemolyticus. In the Southwest of Vietnam, where more than $70 \%$ of Vietnamese shrimp production originated that the disease causes massive curses to shrimp farmers. Some previous published studies have proven that a new type of L-type lectins from Litopenaeus vannamei, named LVLTLC1, can support shrimps innate immune system to counteract the effects of $V$. parahaemolyticus.

Methods- In this study, a new L-type lectin (LVLTLC1)-encoding gene collected from L. vannamei was cloned into pET22b to generate recombinant pET-LVLTLC1 vector. Next, the vector was transformed into E. coli BL21 (DE3) expression host for protein expression.

Results- SDS-PAGE and Western blot immune probed with anti His-tag antibody showed that LvLTLC1 expressed in soluble form. With purity above $73 \%$, recombinant LVLTLC1 protein generated from this study was used to assess the ability to agglutinate V. parahaemolyticus not depending on the attendance of calcium.

Conclusion- The results prompt us to evaluate not only the binding capacity, but also the facilitated bacterial clearance in vivo of the recombinant LVLTLC1 protein. The present work laid the ground work for pathogenic bacteria control in shrimp.
\end{abstract}

Key-words: AHPND, Litopenaeus vannamei, LVLTLC1, recombinant protein, Vibrio parahaemolyticus

\section{INTRODUCTION}

In 2012, there was massive loss in shrimp farming areas in the Southwest of Vietnam, of which the most dangerous is the acute hepatopancreatic necrosis disease (AHPND). According to the General Department of Fisheries (2013), the Southwest of Vietnam region

\section{How to cite this article}

Nguyen PTT, Nguyen LVH, Nguyen TT, Nguyen KLT, Tran-Van H. Cloning, Expression and Purification of Vibrio parahaemolyticus Ltype Lectin from White Leg Shrimp Litopenaeus vannamei for Bacterial Agglutinating. SSR Inst. Int. J. Life Sci., 2020; 6(3): 25442551.

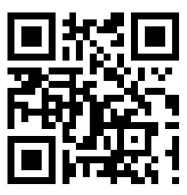

accounts for $90.61 \%$ of brackish water shrimp farming area; $75.2 \%$ of production with 595,723 ha and 358,477 tons. However, with increasing intensity and increasing area, epidemics are becoming more and more widespread and difficult to control, seriously threatening productivity and sustainable development of shrimp farming ${ }^{[1]}$. The pathogen of AHPND in shrimp was identified as $V$. parahaemolyticus strain ${ }^{[2]}$. This strain of bacteria produces two toxins that rapidly destroy tissues and disrupt the hepatopancreas function in the shrimp's digestive system. These cause shrimp die prematurely within 30 days with mortality can reach over $70 \%$. Shrimp can be infected with AHPND throughout the time of the culture, particularly up to 45 days old baby shrimp. 
From the general epidemic situation mentioned above, the combination of many important factors to sustain development shrimp farming industry is necessary. These include research on improving the hatchery and shrimp production process, nutrition and environmental issues. At the same time, it is equally important to find out effective prevention and treatment measures.

Shrimp protecting themselves from serious infectious pathogens depend on the innate immune system like other invertebrates, consist of not only cellular react but also a humoral defense mechanism ${ }^{[3-5]}$. Encapsulation, nodule formation, and phagocytosis are involved the cellular ${ }^{[6]}$. Likewise, the connection between pattern recognition receptors (PRRs) and pathogen-associated molecular patterns (PAMPs) is an essential stage in the immune responses. Different PRRs recognize specific PAMPs and trigger signaling pathways of the immune responses. Surrounded by the diversity of PRRs, lectins have been identified as a potentially important agent in immune defense of shrimp ${ }^{[7]}$. C-type, M-type, L-type, Ptype, fibrinogen-like domain lectins, calreticulin/ calnexin, and galectins are seven types of lectins were found in shrimp ${ }^{[6]}$. However, the insight of lectins function in the immune response system is still unclear, and most of the researches about shrimp lectins up to this point are concentrated on C-type lectin. Excepting LVLTLC1, a newest L-type lectin was identified from $L$. vannamei, exclusively MJLTL1 from tiger prawn Marsupenaeus japonicus ${ }^{[8]}$ has been characterized ${ }^{[9]}$.

L-type lectins, which contain a domain recognizing luminal carbohydrate can interact with $\mathrm{N}$-glycans of glycoproteins ${ }^{[10]}$. A body of evidence has found and demonstrated the immunity support on cultured shrimp of LVLTLC1 when associated with some bacteria including V. parahaemolyticus, the pathogen of AHPND in shrimp, thus promising to be a potential source for AHPND treatment ${ }^{[9]}$. In Vietnam, there has been no research on the effective binding of $V$. parahaemolyticus of LVLTLC1 from white leg shrimp. In the present study, the recombinant L-type lectin from white leg shrimp $L$. vannamei was surveyed the ability of agglutination with AHPND-causing $V$. parahaemolyticus, which serves as the scientific premise for further studies on preventing and treating pathogenic bacteria diseases in shrimp.

\section{MATERIALS AND METHODS}

L. vannamei shrimps were selected from local farms in the Tan Phu Dong Town, Tien Giang Province, Vietnam and extracted at the Department of the Molecular and Environmental Biotechnology, Faculty of Biology and Biotechnology, University of Science, Nation University, Ho Chi Minh City, Vietnam from January 2018 to December 2019. This study isolated all the samples as stated by Tian et al. ${ }^{[9]}$ with adoption.

RNA isolation and cDNA synthesis- White leg shrimps, weighing about $15 \mathrm{~g}$, acquired from the previous day to prepare for the experiments. Grills were collected from healthy shrimp for RNA extraction ${ }^{[9]}$. RNA isolated by NucleoSpin RNA Plus kit (Macherey-Nagel, Germany) was used as the template for amplification of full-length cDNA. The cDNAs were synthesized using the $\mathrm{MyTaq}^{\mathrm{TM}}$ One-Step RT-PCR kit (Bioline, USA). Specific PCR primers (292F Nde and 293R Xho) shows in Table 1 and LvLTLC1 were designed for amplification of the encoding gene. One-step RT-PCR reaction was carried out as follows: 45 $\min$ at $45^{\circ} \mathrm{C}, 1 \mathrm{~min}$ at $95^{\circ} \mathrm{C}$; and 30 cycles of $95^{\circ} \mathrm{C}$ for $15 \mathrm{~s}$, $55^{\circ} \mathrm{C}$ for $15 \mathrm{~s}, 72^{\circ} \mathrm{C}$ for $10 \mathrm{~s}$; and extension for $10 \mathrm{~min}$ at $72^{\circ} \mathrm{C}$. Then, aLvLTLC1 gene after purifying was cloned into a pET22b vector and sequenced by PhusaBiochem, Vietnam.

Table 1: Nucleotide sequences of primers used for amplification

\begin{tabular}{ll}
\hline Primers & Sequence $\left(\mathbf{5}^{\prime} \mathbf{3}^{\mathbf{3}} \mathbf{)}\right.$ \\
\hline 292F Nde & CATATGGATTACATGAAGCGAGAGCAC \\
293R Xho & CTCGAGGTGGAAATATCATATAATTTC \\
T7 promoter & TAATACGACTCACTATAGGG \\
T7 terminator & GCTAGTTATTGCTCAGCGG \\
\hline
\end{tabular}

*Underlined characters showed restriction enzyme

Construction of $p$ ET22b-LvLTLC1 vector- LVLTLC1 gene was created using PCR method using MyTaq $^{\text {TM }}$ Red Mix (Bioline, USA), according to the recommend conditions: $95^{\circ} \mathrm{C}$ for $1 \mathrm{~min}, 30$ cycles $\left(95^{\circ} \mathrm{C}\right.$ for $15 \mathrm{~s}, 55^{\circ} \mathrm{C}$ for $15 \mathrm{~s}$ and $72^{\circ} \mathrm{C}$ for $\left.10 \mathrm{~s}\right)$, and extension at $72^{\circ} \mathrm{C}$ for $10 \mathrm{~min}$. LvLTLC1 was amplified using PCR with primer pairs (292FNde and 293RXho) are shown in Table 1. LvLTLC1 encoding gene was doubly digested with $\mathrm{Ndel}$ and Xhol (Thermo Scientific, USA) before being fused into respective restriction sites in the $p E T 22 b$ plasmid by using the $T 4$ ligase (Thermo Scientific, USA). The ligation product was introduced into E. coli $\mathrm{DH} 5 \alpha$ competent cells. Positive 
transformants were screened with T7 primers. The recombinant plasmid was named pET22b-LvLTLC1. Colony PCR analysis was done to identify the recombinant clones by using T7 primers on a vector.

Expression of LvLTLC1- The recombinant vector, pET22bLVLTLC1, was introduced into the chemically competent E. coli BL21 (DE3) cells to express LVLTLC1 protein ${ }^{[11,12,16-}$ 20]. Bacteria cultured in LB-Amp (Luria-Bertani supplemented with $100 \mu \mathrm{g} / \mathrm{ml}$ ampicillin) medium until $\mathrm{OD}_{600}$ reached 0.4 to 0.6 before inducing without IPTG (in LB-Amp supplemented with $2 \%$ ethanol) for $20 \mathrm{~h}$ at $16^{\circ} \mathrm{C}$. Cells after harvested by centrifugation at $6,000 \mathrm{rpm}$ for 5 min re-suspended in lysis buffer $(0.5 \mathrm{M} \mathrm{NaCl}, 0.02 \mathrm{M}$ $\mathrm{NaH}_{2} \mathrm{PO}_{4}, 0.025 \mathrm{M}$ imidazole, $2 \mathrm{mM}$ dithiothreitol, $10 \%$ glycerol, and $1.5 \%$ Triton X-100) and disrupted by sonication (Microson Misonix incorporation, USA). The cell lysate was centrifuged at 13,000 rpm for $10 \mathrm{~min}$ at $4^{\circ} \mathrm{C}$ to collect the supernatant containing soluble proteins. Total proteins were analyzed by SDS-PAGE and Western blot immune probed with anti His-tag antibody.

LvLTLC1 purification- The supernatant after collected was put on $5 \mathrm{ml}$ His-Trap column, which is combined with the FPLC (ÄKTA, GE Healthcare, USA) ${ }^{[9,16-20]}$. After washing step with binding buffer $(0.5 \mathrm{M} \mathrm{NaCl}, 0.02 \mathrm{M}$ $\mathrm{NaH}_{2} \mathrm{PO}_{4}, 0.025 \mathrm{M}$ imidazole, $2 \mathrm{mM}$ dithiothreitol, $10 \%$ glycerol, and $1.5 \%$ Triton $\mathrm{X}-100$ ), eluted the recombinant proteins from His-Trap column by adding the elution buffer (binding buffer containing 0.5M imidazole). SDSPAGE analyzed eluted protein fractions and the purity of the recombinant proteins was detected by the Gel-Pro Analyzer. The Bradford assay was used to determine protein concentration.

Evaluation the ability of agglutination with AHPNDcausing $V$. parahaemolyticus of LvLTLC1- Gram-negative bacteria AHPND-causing $V$. parahaemolyticus were labeled at room temperature for $1 \mathrm{~h}$ with $2 \mu \mathrm{M}$ Calcein $\mathrm{AM}$, and re-suspended in TBS-Ca buffer (50 mM Tris- $\mathrm{HCl}$, $100 \mathrm{mM} \mathrm{NaCl}, 10 \mathrm{mM} \mathrm{CaCl}$, pH 7.5) at $10^{6} \mathrm{CFU} / \mathrm{ml} .10 \mu \mathrm{l}$ of bacteria and $20 \mu \mathrm{l} \mathrm{LvLTLC1}(0.1 \mathrm{mg} / \mathrm{ml})$ or with a control GST protein $(0.1 \mathrm{mg} / \mathrm{ml})$ were blended together. Then incubating this mixture at $25^{\circ} \mathrm{C}$ for $1 \mathrm{~h}$. Agglutination was observed under fluorescence microscope (Nikon, Japan) at $490 \mathrm{~nm}$ excitation ${ }^{[9]}$. To determine whether agglutination was calciumindependent, calcein AM-labeled microbe was incubated with LVLTLC1 in TBS buffer (TBS-Ca buffer without adding $10 \mathrm{mM} \mathrm{CaCl}_{2}$ ) as described above.

\section{RESULTS}

RNA isolation and cDNA synthesis- Total RNA was successfully extracted from $L$. vannamei following the manufacturer's instructions (Fig. 1A, lane 1). This mRNA was used as the template for amplification of full-length CDNA. The cDNAs were synthesized using specific PCR primers (292F Nde and 293R Xho, Table 1) for LvLTLC1 gene. Using $1.5 \%$ agarose gel electrophoresis to separate the PCR product. The results of the analysis showed that we obtained only a band roughly at $678 \mathrm{bp}$ fragment (Fig. 1B, lane 2), which was consistent with the size of the LVLTLC1 gene. In addition, the negative of the PCR reaction did not attend any contamination of PCR reaction (Fig. 1B, lane 1). This proved that the PCR reaction of the LVLTLC1 gene was not exogenous and the gene fragment was derived from the genome of $L$. vannamei. The DNA fragment was cloned into a pET22b vector and sequenced by PhusaBiochem, Vietnam.
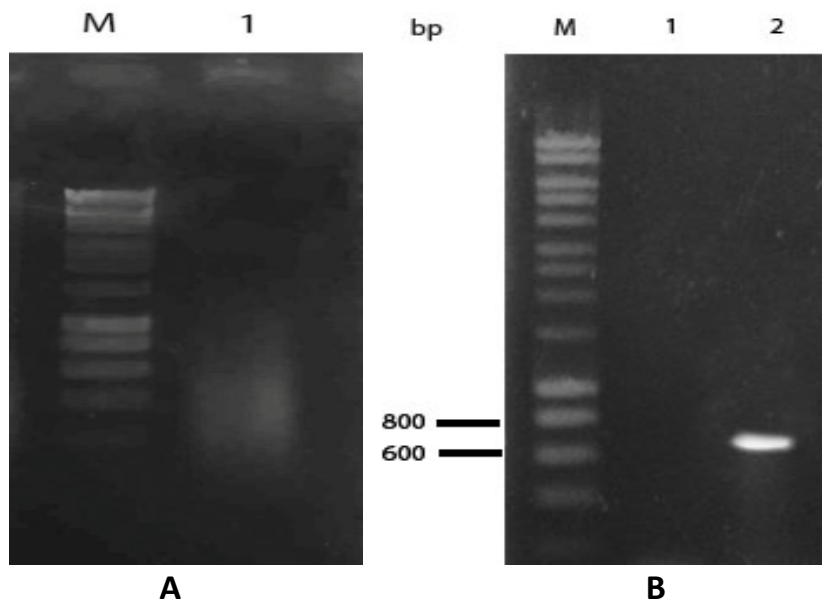

Fig. 1: RNA extraction and cDNA synthesis. RNA extraction

(A): Lane M, 1 kb DNA ladder; lane 1: Shrimp RNAs. A fragment corresponding to the LVLTLC1 amplified by the RT-PCR

(B): Lane M, 1 kb DNA marker; lane 1: Negative control; lane 2: LvLTLC1 fragment

Construction of pET22b-LvLTLC1 vector- The construction of recombinant pET22b-LVLTLC1 was generated as described in materials and methods section. After the gene segments encoding LVLTLC1 were obtained through PCR, one band approximately at 678 bp was observed by agarose gel electrophoresis, indicated amplification of the DNA fragments isolated. 
The PCR fragment containing the LVLTLC1 gene was doubly digested with $\mathrm{Ndel}$ and $\mathrm{Xhol}$ restriction enzymes and then inserted into vector $\mathrm{pET} 22 \mathrm{~b}$ to obtain the expression plasmid pET22b-LvLTLC1. The ligated product was then transformed into $E$. coli strain $(\mathrm{DH} 5 \alpha)$ and was selected on ampicillin-containing medium. By using the T7 primers on vector, colony PCR was chosen to confirm the recombinant colonies (Fig. 2). Colonies containing recombinant vector were given a 978-bp product. The results of electrophoresis showed that there were recombinant colonies suitable to the 978 bp length fragments as design (Fig. 2, lane 3-5). The positive result was due to the insertion of the LVLTLC1 gene into the plasmid pET22b.

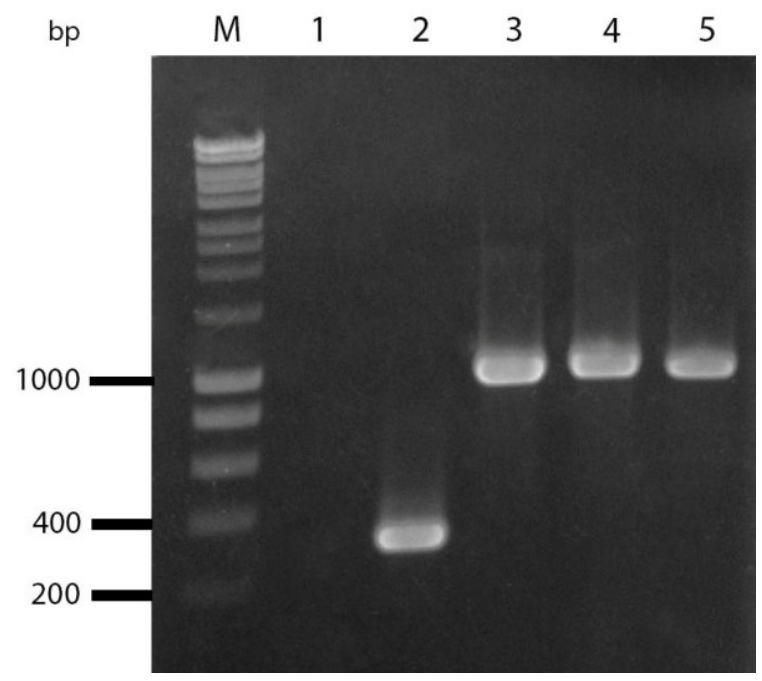

Fig. 2: Confirmation of recombinant clones of $E$. coli $\mathrm{DH} 5 \alpha$ by colony PCR analysis with T7 primers. Lane M, $1 \mathrm{~kb}$ DNA ladder; lane 1, PCR negative control (no DNA); lane 2, negative control (E. coli DH5 $\alpha$ / pET22b); lane 3-5, candidate recombinant clones

To verify cloning precision, the vector was sequenced and aligned with the designed sequence. The alignment showed that the cloned genes were matched with the designed sequence and the LVLTLC1 gene was cloned (Fig. 3).

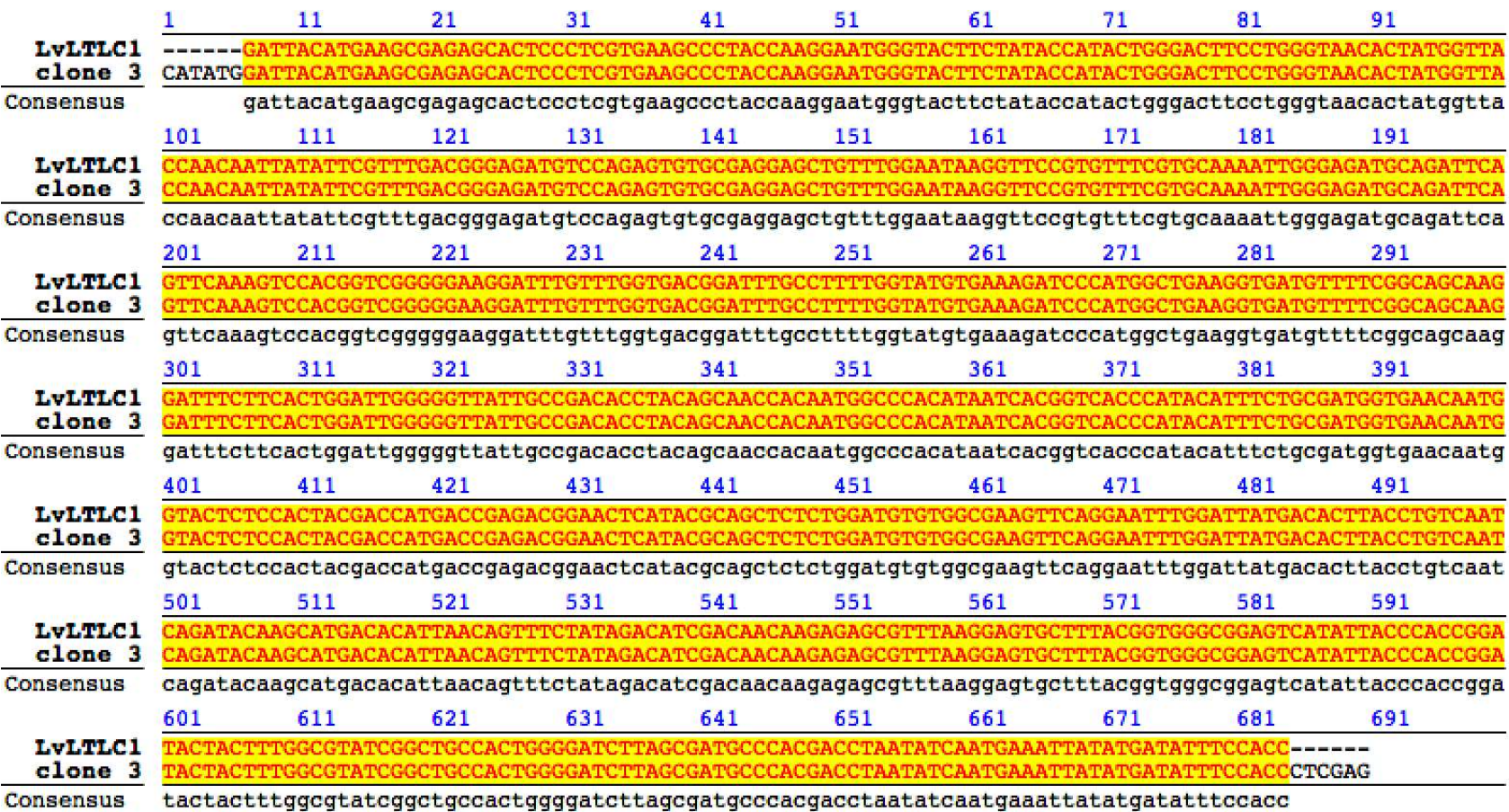

Fig. 3: Sequence alignment between designed gene and a positive clone 
Expression of LvLTLC1- The recombinant plasmid, pET22b-LVLTLC1was introduced into E. coli BL21 (DE3) competent cells which were sequenced using the T7 general primer on the vector, respectively (data not shown). An E. coli BL21 (DE3) colony containing pET22bLVLTLC1 plasmid was induced protein expression without IPTG. Three samples were prepared from induced cells, including total protein samples, soluble samples, and insoluble sample. Negative control, E. coli BL21 (DE3), was induced and collected in the same order. All protein samples were analyzed by SDS-PAGE and Western blot. On the SDS-PAGE gel, the E. coli BL21 (DE3)/ pET22bLVLTLC1 created an accumulated band (Fig. 4A, lane 2) less than $30 \mathrm{kDa}$, while negative control had no similar band (Fig. 4A, lane 1). This band was likely LVLTLC1protein. LVLTLC1 was not visibly detected in the insoluble lane (Fig. 4A, lane 4).

To assure the protein bands on the SDS-PAGE were LVLTLC1, a Western blot with anti $6 x \mathrm{His}$ antibody was performed. Because the LVLTLC1 recombinant protein was designed with $6 \mathrm{xH}$ is at the $\mathrm{C}$-terminal; therefore, it gives a signal on western blot. In the western-blot film, the total and the soluble samples had one band for each (Fig. 4B, lane 2-3), with sizes correlated to bands on the SDS-PAGE gel, and suggested that the proteins were successfully blotted into the membrane. In conclusion, the protein expressed by $E$. coli BL21 (DE3)/ pET22bLVLTLC1 was LVLTLC1 protein.

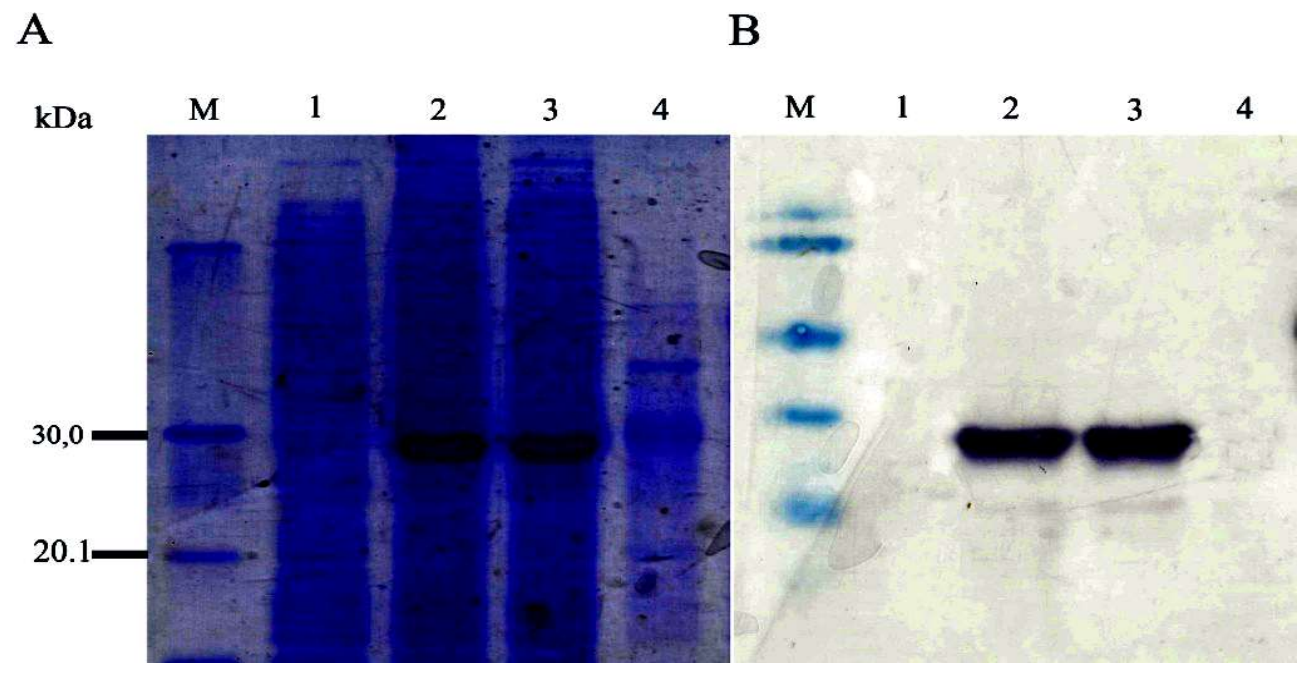

Fig. 4: Analysis of LVLTLC1; (A): SDS-PAGE, (B): Western blot

Lane M, ladder; lane 1: Negative control; 2: Total protein samples; 3: Soluble samples;

4: Insoluble samples

LvLTLC1 purification- After purification, four fractions, including expressed protein sample, flow-through of loading-step, washing-step, and elution-step samples were evaluated by SDS-PAGE. The results (Fig. 5) indicated that the LVLTLC1protein was successfully purified. There was only an accumulated band in the elution sample less than $30 \mathrm{kDa}$ (Fig. 5, lane 4-6) correlated with an over expressed band of the original sample (Fig. 4, lane3). The purity analysis results were performed using Gel Analyzer software. As such, we have initially purified and successfully obtained recombinant LVLTLC1 protein with $73.96 \%$.

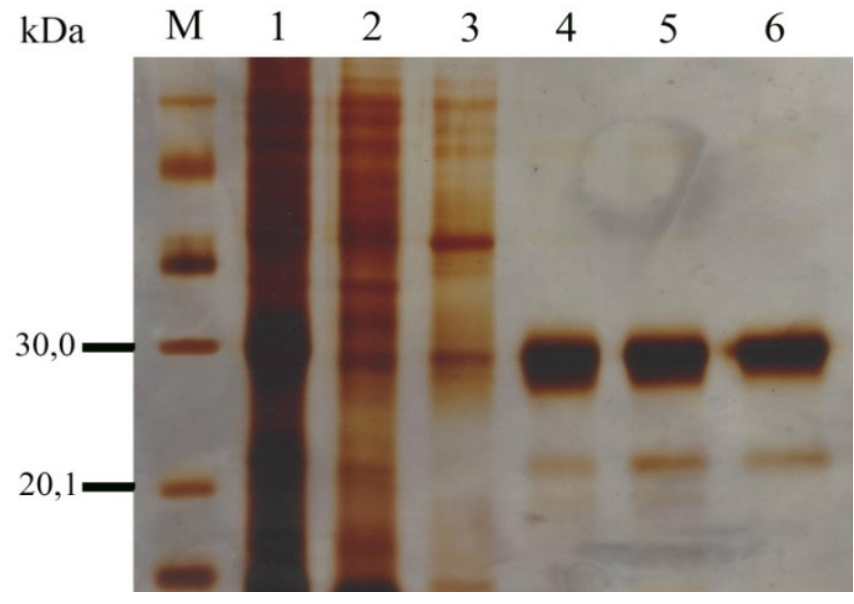

Fig. 5: Purification of LVLTLC1 analyzed by SDS-PAGE. Lane M, ladder; lane 1: Total protein samples; Lane 2: Flowthrough sample; Lane 3: Washing sample; Lane 4-6: Elution samples 
Evaluation the ability of agglutination with AHPNDcausing $V$. parahaemolyticus of LvLTLC1- After incubation with the recombinant protein, bacterial agglutination reaction was observed under a fluorescence microscope. Research results have shown that $V$. parahaemolyticus could be agglutinated by LVLTLC1 (Fig. 6C, 6D), and could not be agglutinated by control protein GST (Fig. 6B). The agglutination capabilities of LVLTLC1 could be clearly observed not depending on the presence of calcium (Fig. 6C) suggested that LVLTLC1 could agglutinate in calciumindependent manner. However, enhanced agglutinating activity shown in bigger agglutinating clumps (Fig. 6D compares to Fig. $6 \mathrm{C}$ ), when calcium was added.
Evaluation the agglutination ability of LvLTLC1 with AHPND-causing $\boldsymbol{V}$. parahaemolyticus- After incubation with the recombinant protein, bacterial agglutination was observed under fluorescent microscope. The results showed that $V$. parahaemolyticus could be agglutinated by LVLTLC1 (Fig. 6C, 6D), and could not be agglutinated by control protein GST (Fig. 6B). The agglutinating activity of LVLTLC1 could be observed without the presence of calcium (Fig. 6C) suggested that LvLTLC1 could agglutinate in calcium-independent manner. However, the addition of calcium enhanced agglutinating activity shown in bigger agglutinating clumps (Fig. 6D compares to Fig. 6C).

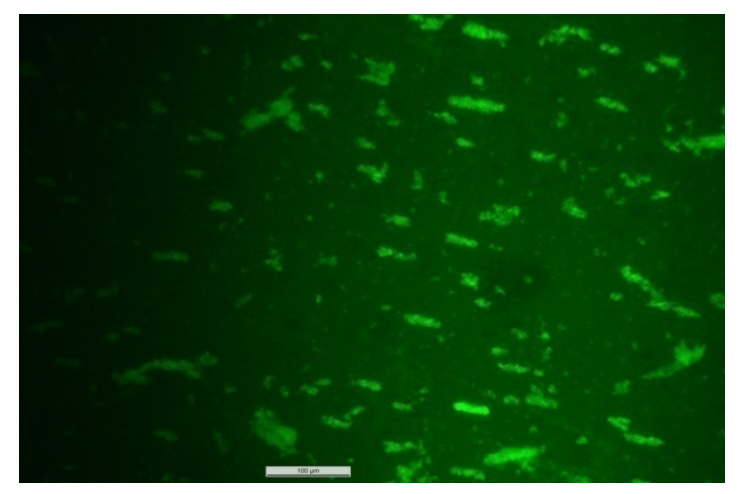

A: V. parahaemolyticus + PBS

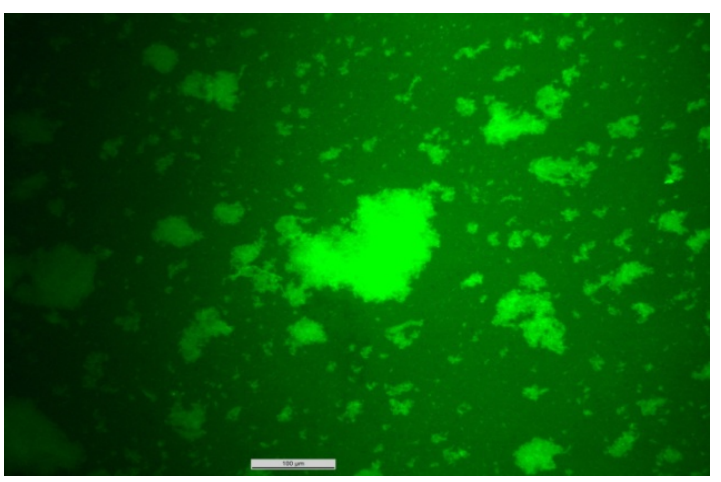

C: V. parahaemolyticus + LVLTLC1

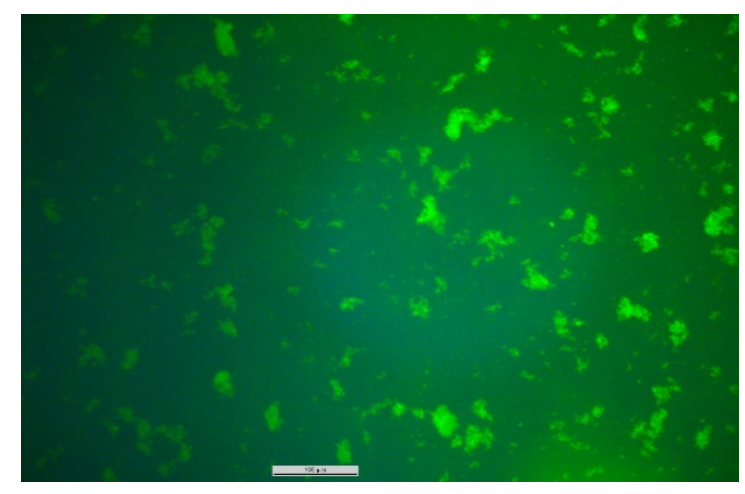

B: V. parahaemolyticus + GST

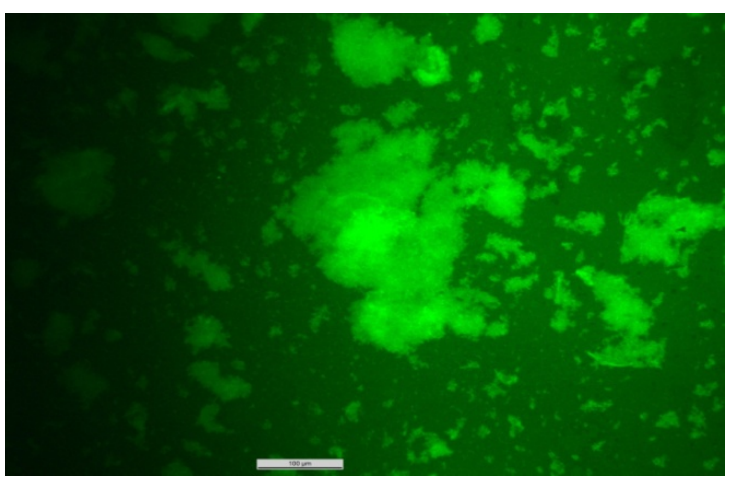

D: V. parahaemolyticus + $\mathrm{LVLTLC1}+\mathrm{Ca}^{2+}$

Fig. 6: $V$. parahaemolyticus agglutinated by LVLTLC1

\section{DISCUSSION}

In this study, the several experimental tests have shown that LVLTLC1 was non-classical inclusion bodies. From these results, sequential steps for increasing the solubility of protein LVLTLC1 were considered. The solubility of protein could be enhanced, when reducing the rate of protein synthesis and reducing the number of hydrophilic interactions may interfere with proper folding of the protein. Firstly, the culture medium supplemented with ethanol ${ }^{[1,12]}$ caused cell to grow slowly down because ethanol had the same effect as the stress agent on $E$. coli ${ }^{[13]}$. Attaching to some small chemical agents could make expression proteins to be probable and widespread application have found in recombinant protein productions ${ }^{[14]}$. This hypothesis was exploited to increase the proportion of recombinant protein expressed in the soluble form ${ }^{[15]}$. Secondly, the expression was led overnight at lower temperature (as low as $16^{\circ} \mathrm{C}$ ) with no IPTG added to expressed LvLTLC1 
because leaky promoter in PET vector causing the gradual secretion of protein into cytoplasm. Thirdly, $10 \%$ glycerol, $1.5 \%$ Triton X-100, and $2 \mathrm{mM}$ dithiothreitol were supplemented with sonication buffer ${ }^{[16]}$. Because of glycerol together with a slow shake could help reduce the number of hydrophilic interactions that may interfere with the proper folding of protein ${ }^{[17,18]}$, and Triton X-100 is a well-known surfactant that increases the solubility of the hydrophobic compound ${ }^{[19]}$. Finally, reducing agent with low concentration when added such as DTT not only prevent the formation of wrong disulfide bonds, but also keeps cysteine side chains in the reduced state. This role analysis buffer by maintaining side chain and protecting the creation of unpredicted disulfide bonds ${ }^{[20]}$.

Before LVLTLC1, like almost of C-type lectins which are classical calcium-dependent lectins ${ }^{[21,22]}$, L-type lectins have a domain which is binding to calcium ${ }^{[23]}$. In the results presented here, LVLTLC1 promoted the capacity of agglutination with V. parahaemolyticus not depending on the attendance of calcium, and the activities of LVLTLC1 were increased when calcium presented. An interesting phenomenon was that LVLTLC1 contains not only maintained calcium-bonding residues of L-type lectin ${ }^{[24]}$ but some differences in amino acid residues, which probably determined the calcium-independence of LVLTLC1 ${ }^{[8]}$. This hypothesis is in line with L-type calcium-dependent lectin MJLTL1 ${ }^{[8]}$ although the calcium-independent lectins-binding carbohydrates via other mechanisms are not fully understood.

\section{CONCLUSIONS}

This research successfully structured the recombinant vector carrying the LVLTLC1 gene (pET-LvLTLC1), which codes LVLTLC1 protein derived from L. vannamei; successfully formed $E$. coli BL21 (DE3) strain carrying pETLVLTLC1 vector capable of expressing recombinant LVLTLC1 protein with $73.96 \%$ purity. Besides, we tested the ability to bind $V$. parahaemolyticus pathogenic bacteria of LVLTLC1. Data showed that LVLTLC1 could agglutinate AHPND-causing $V$. parahaemolyticus not depending on the attendance of calcium.

On the other hand, the product from this research could be used as a supply of recombinant protein LVLTLC1 for further researches in evaluating the immune-supporting activity of LVLTLC1, towards the development of products preventing and treating AHPND in shrimp.

\section{ACKNOWLEDGMENTS}

This research was supported by a grant funded by the Tien Giang University (Grant number: T2015-14).

\section{CONTRIBUTION OF AUTHORS}

Research concept- Phuong-Thao Thi Nguyen, Hieu TranVan

Research design- Phuong-Thao Thi Nguyen, Hieu TranVan

Supervision- Hieu Tran-Van

Materials- Kim-Loan Thi Le, Phuong-Thao Thi Nguyen, Hieu Tran-Van

Data collection- Phuong-Thao Thi Nguyen, Lan-Vy Hoai Nguyen, Thang Tan Nguyen, Kim-Loan Thi Le

Data analysis and Interpretation- Phuong-Thao Thi Nguyen, Lan-VyHoai Nguyen, Thang Tan Nguyen, KimLoan Thi Le, Hieu Tran-Van

Literature search-Phuong-Thao Thi Nguyen, Lan-Vy Hoai Nguyen

Writing article, critical review, article editing-PhuongThao Thi Nguyen, Hieu Tran-Van

Final approval- Hieu Tran-Van

\section{REFERENCES}

[1] Flegel TW. Historic emergence, impact and current status of shrimp pathogens in Asia. J. Invertebr. Pathol., 2012; 110(2): 166-73.

[2] Tran L, Nunan L, Redman RM, Mohney LL, Pantoja $C R$, et al. Determination of the infectious nature of the agent of acute hepatopancreatic necrosis syndrome affecting penaeid shrimp. Dis. Aquat. Organ., 2013; 105(1): 45-55.

[3] Li F, Xiang J. Recent advances in researches on the innate immunity of shrimp in China. Dev. Comp. Immunol., 2013; 39(1-2): 11-26.

[4] Walker PJ, Winton JR. Emerging viral diseases of fish and shrimp. Vet. Res., 2010; 41(6): 51.

[5] De Schryver P, Defoirdt T, Sorgeloos P. Early Mortality Syndrome Outbreaks: A Microbial Management Issue in Shrimp Farming?. PLoS. Pathog., 2014;10(4): e1003919.

[6] Iwanaga S, Lee BL. Recent advances in the innate immunity of invertebrate animals. J. Biochem. Mol. Biol., 2015; 38(2): 128-50.

[7] Nyholm SV, Graf J. Knowing your friends: Invertebrate innate immunity fosters beneficial bacterial symbioses. Nat. Rev. Microbiol., 2012; 10(12): 815 . 
[8] Xu S, Wang L, Wang XW, Zhao YR, Bi WJ, et al. L-Type lectin from the kuruma shrimp Marsupenaeus japonicus promotes hemocyte phagocytosis. Dev. Comp. Immunol., 2014; 44(2): 397-405.

[9] Tian $Y$, Chen T, Huang W, Luo P, Huo D, et al. A new L-type lectin (LVLTLC1) from the shrimp Litopenaeus vannamei facilitates the clearance of Vibrio harveyi. Fish. Shellfish. Immunol., 2018;73: 185-91.

[10]Kamiya Y, Kamiya D, Yamamoto K, Nyfeler B, Hauri $\mathrm{HP}$, et al. Molecular basis of sugar recognition by the human L-type lectins ERGIC-53, VIPL, and VIP36. J. Biol. Chem., 2008; 283(4): 1857-61.

[11]Dinnbier U, Limpinsel E, Schmid R, Bakker EP. Transient accumulation of potassium glutamate and its replacement by trehalose during adaptation of growing cells of Escherichia coli K-12 to elevated sodium chloride concentrations. Arch. Microbiol., 1988; 150(4): 348-57.

[12]Nieba L, Honegger A, Krebber C, Plückthun A. Disrupting the hydrophobic patches at the antibody variable/constant domain interface: Improved in vivo folding and physical characterization of an engineered scFv fragment. Protein. Eng., 1997; 10(4): 435-44.

[13]Chhetri G, Kalita P, Tripathi T. An efficient protocol to enhance recombinant protein expression using ethanol in Escherichia coli. Methods X., 2015; 2: 38591.

[14] Graslund S, Nordlund P, Weigelt J, Hallberg BM, Bray $\mathrm{J}$, et al. Protein production and purification. Nat. Methods, 2008; 5(2): 135.

[15]Grunberg-Manago M. Messenger RNA Stability and Its Role in Control of Gene Expression in Bacteria and Phages. Annu. Rev. Genet., 1999; 33(1): 193-227.
[16]Esmaili I, Mohammad Sadeghi HM, Akbari V. Effect of buffer additives on solubilization and refolding of reteplase inclusion bodies. Res. Pharm. Sci., 2018; 13(5): 413.

[17]Vagenende V, Yap MG, Trout BL. Mechanisms of protein stabilization and prevention of protein aggregation by glycerol. Biochem., 2009;48(46): 11084-96.

[18]Al-Samarrai TH, Jones WT, Harvey D, Kirk CA, Templtone M. Effect of $4 \%$ glycerol and low aeration on result of expression in Escherichia coli of Cin3 and three Venturia EST's recombinant proteins. Am. J. Mol. Biol., 2013; 3: 1-9.

[19]Farsang E, Gaal V, Horvath O, Bardos E, Horvath K. Analysis of non-ionic surfactant Triton X-100 using hydrophilic interaction liquid chromatography and mass spectrometry. Mol., 2019; 24(7): 1223.

[20]Kelly ST, Zydney AL. Effects of intermolecular thioldisulfide interchange reactions on bsa fouling during microfiltration. Biotechnol. Bioeng., 1994; 44(8): 972-82.

[21]Cambi A, Koopman M, Figdor CG. How C-type lectins detect pathogens. Cell. Microbiol., 2005; 7(4): 48188.

[22]Zelensky AN, Gready JE. The C-type lectin-like domain superfamily. FEBS. J., 2005; 272(24): 617917.

[23]Hart GW, Akimoto Y. Essentials of Glycobiology. $2^{\text {nd }}$ Ed., USA; Cold Spring Harbor Laboratory Press, 2009.

[24]Mojica ER, Merca FE. Lectin from the Body Walls of Black Sea Cucumber (Holothuria atra Jaeger). Philipp. J. Sci., 2004; 133(2): 77. 